\title{
Development of Natural Cation Exchanger for the Treatment of Lead ions from Aqueous Solution
}

\author{
Puspa Lal Homagai* \\ Central Department of Chemistry, Tribhuvan University, Kirtipur, Kathmandu, Nepal \\ E-mail: homagaipl@gmail.com
}

\begin{abstract}
Cellulose, hemicelluloses and lignin are the main constituents found in sugarcane (Saccharum officinarum) bagasse having many surface active sites containing hydroxyl and/or phenolic groups which are effective for chemical modification. The biowaste was first charred with concentrated sulphuric acid and then the charred aminated sugarcane bagasse (CASB) was prepared by reduction followed by oxidation. The developed bio-sorbent was characterized by SEM, TGA/DTA, FTIR and elemental analysis. Batch adsorption methods were carried out to determine $\mathrm{Pb}^{+2}$ sorption capacities at different $\mathrm{pH}$ ranges and sorbate concentrations. The maximum adsorption capacity for $\mathrm{Pb}^{+2}$ was found to be 323 $m g g^{-1}$ with an efficiency of $98 \%$ at $\mathrm{pH}$ 4.The experimental data showed a good fit to Langmuir isotherm as compared to Freundlich isotherm models. The kinetics was best fitted with the pseudo-second order model. The adsorption equilibrium was attained within $20 \mathrm{~min}$. The high adsorption capacity and fast kinetics results of the charred aminated sugarcane bagasse indicated that it might be potential adsorbent for the removal of lead from contaminated water.
\end{abstract}

Keywords: Charred aminated sugarcane bagasse, Lead, Isotherms, Adsorption.

\section{Introduction}

Presence of heavy metals in the environment is a serious pollution problem that has been and still is a focus of attention all over the world. Contamination of soils, groundwater, surface water and air with hazardous and toxic chemicals poses significant problems for human health and the environment. Heavy metals are considered to be particularly dangerous pollutants for all living beings. Their presence in the wastewater of several industrial processes, such as electroplating, metal finishing, metallurgical work, tanning, chemical manufacturing, mining and battery manufacturing, has brought about more environmental concerns due to their toxicity even at low concentration. Since heavy metals are nonbiodegradable and they can be accumulated in living tissues, causing various diseases and disorders; therefore they must be removed before discharge. Lead has been cited as one of the three most toxic metals that have latent long-term negative impacts on health, causing anemia, encephalopathy, hepatitis and nephritic syndrome. Different conventional techniques like ion-exchange, membrane separation, lime precipitation, reverse osmosis, solvent extraction, electro-dialysis and adsorption are often used for the separation of heavy metals. The application of low-cost adsorbents obtained from agricultural byproducts ${ }^{1-5}$ widely used in the recent research as a replacement for costly conventional methods of removing heavy metal ions from wastewater. The bio-sorbent obtained from plant wastes are environmentally friendly in comparison to synthetic adsorbent in the incineration process. It is well known that all plant materials are composed of cellulosic network which can be easily converted into required modification. Recently, much attention is given to prepare adsorbents from various wastes generated from forestry ${ }^{6}$ and fishery ${ }^{7-8}$. In Nepal, sugarcane industries produce a large amount of

\footnotetext{
* Corresponding author
} 
sugarcane bagasse (SB) as a byproduct which is found free of cost and that requires little chemical processing to increase its sorptive capacity, hence its cost is supposed to be low even after chemical modification. The main constituents of sugarcane bagasse are cellulose $(46.0 \%)$, hemicellulose $(24.5 \%)$ and lignin ${ }^{9}(19.95 \%)$ The polysaccharides found in sugarcane bagasse are biopolymers having many hydroxyl and/ or phenolic groups that can be chemically modified to form new compounds with changed properties $^{10-11}$. Although there are some reports of raw sugarcane bagasse as the adsorbent ${ }^{12-13}$, however, owing to its low adsorption capacity, we have explored a simple means of chemical modification to enhance its metal adsorption properties in the present study. The study of bagasse as an adsorbent to reduce the environmental pollutants has also received much attention recently 5,14 .

On the other hand, the application of raw plant wastes as adsorbents can bring a lot of problems due to release of soluble organic compounds contained in the plant materials ${ }^{6}$. The soluble organic compounds may increase COD, BOD and TOC which causes depletion of oxygen content in water and can threaten the life. Therefore, plant wastes need to be modified chemically before being applied for the removal of heavy metals. In general, the chemically modified plant wastes exhibit surface complex formation, ion exchange, and chelation that have been considered as the important adsorption mechanisms for heavy metal sequestration. It has been reported that adsorbents with carboxyl, sulphonic, and phosphoric groups on the surface favor metal ion adsorption through the ion exchange mechanism while those containing nitrogen on the surface with amino group facilitate metal ion adsorption through the chelation mechanism.

The main objective of this research work is to introduce an amine functional group onto the cellulosic backbone present in sugarcane bagasse. The nitrogen atom contained in charred aminated sugarcane bagasse has a greater tendency to form stable complexes with heavy metal ions to sequester them from aqueous solution. The adsorbent CASB is derived from natural polysaccharides which is easy to be incinerated in comparison to commercial ion exchange resin made up of plastic materials. Furthermore, the comparative adsorption capacity of $\mathrm{Pb}$ (II) ions onto different chemically modified adsorbent has been enlightened.

\section{Experimental Methods}

\section{Preparation of adsorbent material}

Locally collected sugarcane bagasse (SB) from Baneshwor juice centre, Kathmandu was cut into small pieces and dried under sunlight and then kept in air oven at $60^{\circ} \mathrm{C}$ for $24 \mathrm{~h}$. The dried sample was grounded into fine particles with uniform size of $212 \mu \mathrm{m}$. The bagasse powder was treated with concentrated $\mathrm{H}_{2} \mathrm{SO}_{4}$ and left for overnight. It was washed with deionized water until neutrality and drying it is referred as charred sugarcane bagasse (CSB). It is known to us that acid treatment with such biopolymer creates a suitable environment for its ring opening ${ }^{15}$. In addition to dehydrating property of acid, such materials were found to be effective for further chemical modifications. In this regard, the charred material was aminated adding sodium dithionite, pyridine and ammonia at $20^{\circ} \mathrm{C}$ followed by nitration and left for overnight. It was washed till neutrality and dried at $70^{\circ} \mathrm{C}$ and finally kept in desiccator. This material is ready for the experiments and called as charred aminated sugarcane bagasse (CASB).

\section{Chemicals}

All reagents and chemicals (Wako Chem. Ltd. Japan) used in this study were analytical grade. Appropriate amount of lead nitrate salt was dissolved to prepare $1000 \mathrm{mg} / \mathrm{L}$ standard stock solutions. The working solutions of different concentrations were diluted using $0.1 \mathrm{M} \mathrm{HNO}_{3}$. The $\mathrm{pH}$ of experimental solution was adjusted using $0.1 \mathrm{M} \mathrm{NaOH}$ and $0.1 \mathrm{M} \mathrm{HNO}_{3}$ whereas 2-[4-(2- Hydroxymethyl) -1piperazinyl] ethanesulfonic acid (HEPES) was used as a buffering reagent. 


\section{Adsorption experiments}

The $\mathrm{pH}$ of the working solutions of lead (II) was adjusted by adding either small amount of nitric acid or sodium hydroxide after adding $0.1 \mathrm{M}$ of HEPES as a buffering agent. In the batch-wise experiments, $20 \mathrm{mg}$ of dried adsorbent was taken into $50 \mathrm{ml}$ Erlenmeyer flask with $15 \mathrm{ml}$ test solution maintaining the concentration of $50 \mathrm{mg} / \mathrm{L}$. The flasks were shaken vigorously in a thermostated shaker (Thermostatic Shaking Incubator AT 24R, Japan) at $303 \mathrm{~K}$ and $150 \mathrm{rpm}$ for $24 \mathrm{~h}$ to attain the equilibrium. The initial and equilibrium concentrations of the metal ions were measured by using Shimadzu AA-6650 Atomic Absorption Spectrophotometer (AAS). The adsorption efficiency, A\% of the metal ion was calculated from equation (1).

$$
A \%=\frac{C_{i}-C_{e}}{C_{i}} \times 100
$$

The sorption capacity of metal ions is the concentration of the metal ions on the adsorbent and can be calculated based on the mass balance principle using equation (2).

$$
q=\frac{\mathrm{C}_{i}-\mathrm{C}_{\mathrm{e}}}{\mathrm{W}} \times \frac{\mathrm{L}}{1000}
$$

In the above equations, $\mathrm{q}$ represents the amount of metal uptake per unit mass of the adsorbent $\left(\mathrm{mg} \mathrm{g}^{-1}\right), \mathrm{L}$ is the volume of the test solution $(\mathrm{mL}), \mathrm{W}$ is the dry mass of the adsorbent $(\mathrm{g}), \mathrm{C}_{\mathrm{i}}$ and $\mathrm{C}_{\mathrm{e}}$ the initial and final concentrations $\left(\mathrm{mg} \mathrm{dm}^{-3}\right)$, respectively.

\section{Results and Discussion}

\section{SEM analysis}

The surface morphologies of CSB and CXSB were observed by using a scanning electron microscopy (SEM) using an S-3000N Scanning Electron Microscope of HITACHI, Japan. The fiber surface of CSB was found to be relatively rough and non-uniform due to hydrolysis reaction on the surface of SB by the action of concentrated sulphuric acid. The surface morphology of CSB and CASB was characterized by SEM images shown in Fig. 1(a) and 1(b). It can be seen that the external surface of CASB is full of cavities like a honeycomb structure containing isolated and irregular pores. Amination of charred sugarcane sufficiently enhanced the morphology of CSB and its physical, chemical and biodegradable characteristics which vary with respect to the nature of synthetic side chains incorporated.


Figure 1: SEM images showing the surface morphologies of (a) CSB before modification and (b)CASB after modification. 


\section{FTIR Characterization}

FTIR spectrophotometer (FT/IR-410 (JASCO, Japan) was used to identify the functional groups present in a bio-adsorbent. The spectra in the $3500-400 \mathrm{~cm}^{-1}$ regions are shown in Fig. 2a and $2 \mathrm{~b}$ for CSB and CASB. The modification of CSB with $\mathrm{Na}_{2} \mathrm{~S}_{2} \mathrm{O}_{4}$ and $25 \% \mathrm{NH}_{3}$ transforms CSB to CASB. In this transformation many characteristics bands are shifted at the maximum peak, and absorbance is changed. The peak observed at $3484 \mathrm{~cm}^{-1}$ is due to the stretching vibration of the $\mathrm{O}-\mathrm{H}$ groups. Although there is possibility of overlapping between the $\mathrm{N}-\mathrm{H}$ and the $\mathrm{O}-\mathrm{H}$ stretching vibrations, the strong broad band at the wave number region of $3300-3500 \mathrm{~cm}^{-1}$ is characteristic of the $\mathrm{N}-\mathrm{H}$ stretching vibration. The significant decrease of transmittance in this band region after lead adsorption indicates that the N-H

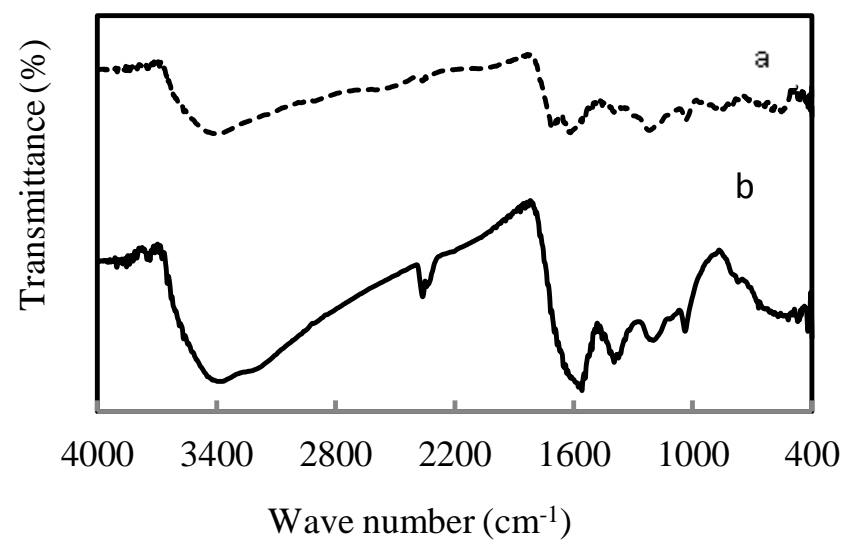

Figure 2: FTIR of (a) CSB an (b) CASB

vibration was affected due to lead adsorption. Other changes in the transmittance can be observed at the wave number of $1720,1644,1457,1251,1049$ and $902 \mathrm{~cm}^{-1}$, respectively. These wave numbers are closely related to the $\mathrm{N}-\mathrm{H}$ bending, $\mathrm{C}-\mathrm{N}$ stretching, and $\mathrm{N}-\mathrm{H}$ rocking bands. The board and strong band ranging from 3300-3500 $\mathrm{cm}^{-1}$ may be due to overlapping of $\mathrm{O}-\mathrm{H}$ and $\mathrm{N}-\mathrm{H}$ stretching, which is consistent with the peaks at 1644 and $1047 \mathrm{~cm}^{-1}$ assigned to alcoholic C-O and C-N stretching vibration ${ }^{16}$. Prior to modification of CSB the band at $1720 \mathrm{~cm}^{-1}$ is due to the $-\mathrm{CHO}$ group formed during the charring process. This peak disappears after modification of CSB into CASB and an intense broad band depicted in Fig. 2(b) is observed at $1592 \mathrm{~cm}^{-1}$ revealing that amino group has been introduced onto CSB. The amount of carbon, hydrogen and nitrogen in CSB and CASB were found to be different from the raw sugarcane bagasse (RAW) is depicted in the Table1. After amination, the increased percentage of nitrogen confirmed that there was proper modification of charred sugarcane bagasse by the introduction of amine group.

\section{Thermal analysis}

The thermal stability and degradation behavior of CSB and CASB samples were evaluated by thermo gravimetric analysis (TGA) and differential thermogravimetric analysis (DTA) in a $\mathrm{N}_{2}$ atmosphere using a thermal analyzer(Model TG/ DTA 6300, Seiko Instrument Inc. Extar 6000). Charred sugarcane bagasse degraded mainly two stages such as devolatilization and solid decomposition, the first at $230{ }^{\circ} \mathrm{C}$ and last one at $430{ }^{\circ} \mathrm{C}$. The first step can be assigned to decomposition of fibers and second corresponds to the complete decomposition. Same way CASB also showed two decomposition steps at $250{ }^{\circ} \mathrm{C}$ and $520^{\circ} \mathrm{C}$, respectively. These results are depicted in the TGA and DTA curves shown in Fig. 3(a) \& (b) for CSB and CASB, respectively. The first stage started at about $100^{\circ} \mathrm{C}$ for all the materials with weight loss of 10- 
$20 \%$ due to loss of physically adsorbed water on membrane surfaces. The second stage exhibited a rapid weight loss at $230-430{ }^{\circ} \mathrm{C}$ and $250-520^{\circ} \mathrm{C}$ for CSB and CASB, respectively. The maximum oxidation reached at $430{ }^{\circ} \mathrm{C}$ for $\mathrm{CSB}$ and $520^{\circ} \mathrm{C}$ for CASB. The second degradation stage of CASB took place at higher temperatures than the corresponding stage of CSB indicating that CSB is less stable than CASB. The weight loss for CSB $\left(230-430^{\circ} \mathrm{C}\right)$ and CASB $\left(250-520^{\circ} \mathrm{C}\right)$ were found to be about $85 \%$ and $82 \%$, respectively. The DTA curves revealed interesting and more accurate differences of the thermal behavior of the CSB and CASB than the TGA curves. The DTA peak of CASB had shown its maximum value at about $520^{\circ} \mathrm{C}$, while it is $430^{\circ} \mathrm{C}$ for CSB indicating a strong evident in the increase in thermal stability of the CASB over CSB. From the aforementioned analysis it is concluded that chemical modification has taken place within the CSB.
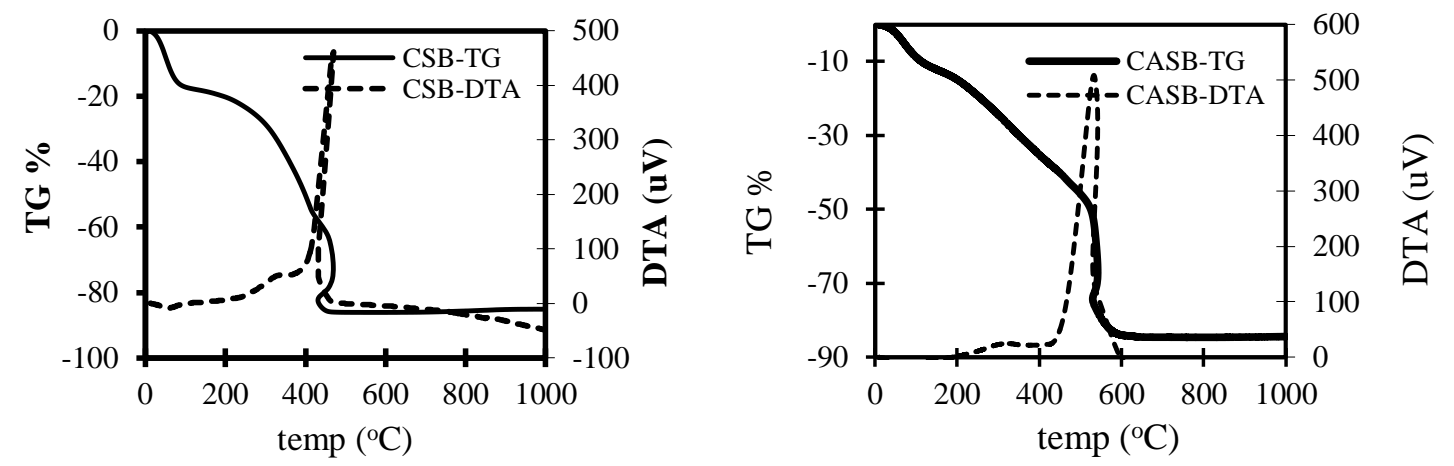

Figure 3: TG-DTA curves of (a) CSB ( before modification)and (b) CASB(after modification)

Table 1: Elemental analysis of sugarcane bagasse before and after modification

\begin{tabular}{ccccc}
\hline Adsorbents/Elements & Carbon (\%) & Hydrogen (\%) & Nitrogen (\%) & Sulphur (\%) \\
\hline RSB & 46.58 & 5.95 & 0.23 & 0.32 \\
\hline CSB & 50.24 & 3.65 & 0.51 & 2.46 \\
\hline CASB & 49.41 & 2.99 & 6.29 & 3.01 \\
\hline
\end{tabular}

\section{Effect of $p H$}

The removal of metal ion from aqueous solution by adsorption is dependent on solution's $\mathrm{pH}$ and, since it affects adsorbent surface charge, on the degree of ionization, and on the adsorbates species. The solution $\mathrm{pH}$ was measured before and after adsorption of metal ions from aqueous solution by using a $\mathrm{pH}$ meter (HM- 30R, TOA-DKK). At low $\mathrm{pH}$, there is high concentration of $\mathrm{H}^{+}$that has high mobility as compared to metal ions and competition between $\mathrm{H}^{+}$with metal ions decreases their adsorption. On the other hand, as the $\mathrm{pH}$ value of the solution increases, adsorption also increases due to lesser number of $\mathrm{H}^{+}$and greater number of surface ligands with negative charges. The low adsorption of metal ions at low $\mathrm{pH}$ may be due to sorbate lyophobic behavior ${ }^{17}$. In the same way, the solubility of metal in solution decreases with increasing $\mathrm{pH}$ and the sorption increases with increasing of $\mathrm{pH}$. The optimum $\mathrm{pH}$ for $\mathrm{Pb}$ (II) was found to be 4 for all adsorbents where adsorption efficiency of CASB was evaluated $98 \%$.The adsorption capacities onto raw sugarcane bagasse (RSB), CSB and CASB were compared to find out 
maximum sequestration of lead (II) ion from the aqueous solution at different $\mathrm{pH}$ ranges which is shown in Fig.4.
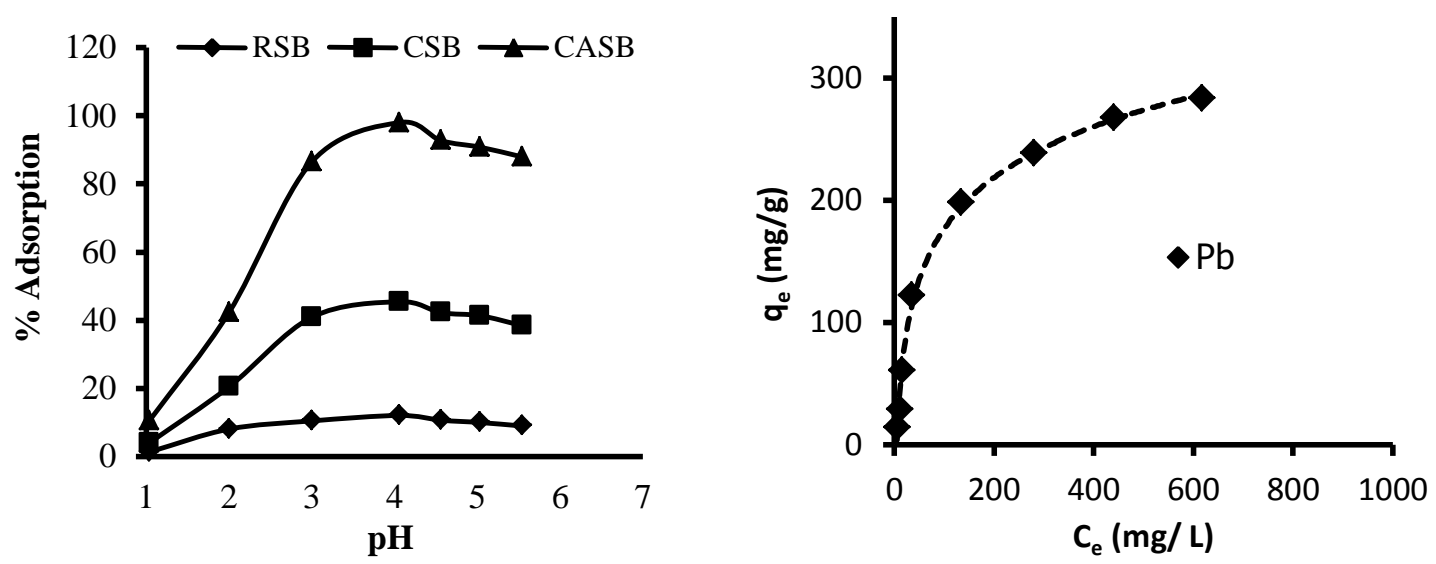

Figure 4 (left): Adsoption Pb(II) ion as a function of $p H$ onto RSB, CSB and CASB. Figure 5 (right): Adsorption isotherm plot for the adsorption of $\mathrm{Pb}^{2+}$ ions onto $C A S B$.

\section{Adsorption isotherms}

Adsorption isotherms describe how adsorbates interact with adsorbents and are important in optimizing the use of the bio-sorbent. The functionalized adsorbent CASB has been allowed to react with aqueous solution of $\mathrm{Pb}(\mathrm{II})$ for the attainment of equilibrium state. Here isotherm studies were performed using various concentrations of the metal ion ranging from 25 to $1000 \mathrm{mg} / \mathrm{L}$. For batch adsorption experiment, $20 \mathrm{mg}$ of adsorbent was equilibrated with $15 \mathrm{ml}$ of synthetic lead (II) solution in $50 \mathrm{ml}$ Erlenmeyer flask for $24 \mathrm{~h}$ to attain equilibrium. All the adsorption data were tested with the Langmuir isotherm and Freundlich isotherm model using the linear form as represented by Eqs. (3) and (4).

$$
\begin{aligned}
& \frac{C_{\mathrm{e}}}{\mathrm{q}_{\mathrm{e}}}=\frac{\mathrm{Ce}}{\mathrm{q}_{\mathrm{m}} \mathrm{b}}+\frac{\mathrm{C}_{\mathrm{e}}}{\mathrm{q}_{\mathrm{m}}} \\
& \ln \mathrm{q}_{\mathrm{e}}=\ln \mathrm{K}_{\mathrm{F}}+\frac{1}{\mathrm{n}} \ln \mathrm{C}_{\mathrm{e}}
\end{aligned}
$$

Where $\mathrm{C}_{\mathrm{e}}(\mathrm{mg} / \mathrm{L})$ is the equilibrium concentration of metal ion in aqueous solution and $q_{\mathrm{e}}$ is the amount lead adsorbed at equilibrium $(\mathrm{mg} / \mathrm{g})$. The Langmuir constant $\mathrm{q}_{\mathrm{m}}(\mathrm{mg} / \mathrm{g}$ ) represent the monolayer adsorption capacity, $\mathrm{b}\left(\mathrm{L} / \mathrm{mg}\right.$ ) the binding constant, $\mathrm{n}$ (dimensionless) a constant of adsorption intensity and $\mathrm{K}_{\mathrm{F}}$ $(\mathrm{L} / \mathrm{mg})$ is Freundlich constant characterizing the adsorption capacity. To examine the relationship between the metal sorption capacity $\left(\mathrm{q}_{\mathrm{e}}\right)$ and the metal ions at equilibrium $\left(\mathrm{C}_{\mathrm{e}}\right)$, the sorption equilibrium data for lead was compared to Langmuir and Freundlich isotherms models, where the Langmuir and Freundlich constants and its correlation coefficients evaluated from the isotherm for $\mathrm{Pb}^{+2}$ are given in Table 2. The sorption characteristics of the metal ions on the CASB followed more closely the Langmuir isotherm model than the Freundlich isotherm model. The high value of Langmuir correlation coefficient confirmed that the Langmuir isotherm is best fitted than the Freundlich isotherm onto CASB. The maximum adsorption capacity based on experimental results as shown in Figure 5 found to be $267 \mathrm{mg} / \mathrm{g}$. 
On the other hand, the theoretical maximum monolayer capacity $\left(\mathrm{q}_{\mathrm{m}}\right)$ of the metal ions based on Langmuir adsorption equation was determined to be $323 \mathrm{mg} / \mathrm{g}$ from Figure 6 . This result is in close agreement against each other suggesting that lead like heavy metal can be quantitatively sequestered onto CASB. The adsorption sites for the mentioned metals are at nitrogen atoms of attached to amine groups. The complexation mechanism of the metal ions with the amino group is taken place through ion exchange process. According to HSAB theory, aminated biosorbent acts as soft bases tends to form stable complexes with heavy metals such as $\mathrm{Pb}$ (II), thus CASB will have a much higher affinity and sorption capacity as compared to that of raw biomass. The essential characteristics and the feasibility of the Langmuir isotherm in terms of a dimensionless constant, separation factor or equilibrium parameter $R_{L}$, which is defined as by Eq. (5)

$$
\mathrm{R}_{\mathrm{L}}=1 /(1+\mathrm{bCi})
$$

The $R_{L}$ value indicates the shape of the isotherm as $R_{L}>1$ : unfavourable, $R_{L}=1$ : linear , $0<R_{L}>1$ : favourable, $R_{L}=0$ : irreversible adsorption. The value of $R_{L}$ found to be 0.8711 by calculating the data of $\mathrm{b}$, taking initial that concentration of sorbate and concluded that Langmuir adsorption isotherm is favourable .

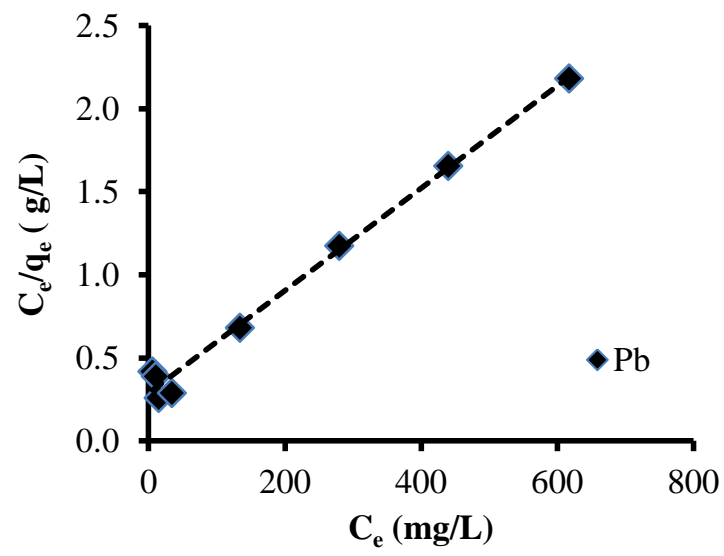

Figure 6: Langmuir isotherm plot for adsorption of $\mathrm{Pb}^{2+}$ ion onto $\mathrm{CASB}$

Table 2: $P b(I I)$ adsorption onto CASB for different constants of Langmuir and Freundlich isotherms

\begin{tabular}{|c|c|l|l|l|l|l|}
\hline \multicolumn{2}{|c|}{ Langmuir model } & \multicolumn{3}{c|}{ Freundlich model } \\
\hline $\mathrm{q}_{\mathrm{m}}(\mathrm{mg} / \mathrm{g})$ & $\mathrm{R}^{2}$ & $\mathrm{~b}(\mathrm{~L} / \mathrm{g})$ & $\mathrm{R}_{\mathrm{L}}$ & $\mathrm{K}_{\mathrm{f}}$ & $\mathrm{n}$ & $\mathrm{R}^{2}$ \\
& & & & & & \\
\hline 323 & 0.990 & 0.0059 & 0.8711 & 1.063 & 1.154 & 0.807 \\
\hline
\end{tabular}

\section{Sorption kinetics}

The rate of metal sorption is an important factor and a prerequisite for the determination of a successful practical adsorption application. The kinetic results of the adsorption of metal ions onto CASB are shown in Fig7. The sorption kinetics of the metal ions onto CASB was analyzed as the function of 
time at an initial concentration of $100 \mathrm{mg} / \mathrm{L}$ solutions. The concentrations of the metal ions were analyzed keeping their optimum $\mathrm{pH} 4$ in a regular and certain interval of time by AAS. From the experimental data, it is observed that the percentage of adsorption increased with the increase in time from 5 to 20 min and then it became constant in the range from $20 \mathrm{~min}$ to $240 \mathrm{~min}$. The pseudo-second order kinetics model has often been used to fit the experimental kinetic adsorption data. The linearized pseudo-second order kinetic equation ${ }^{18}$ is used as the following form:

$$
\frac{t}{\mathrm{q}_{\mathrm{t}}}=\frac{1}{K_{2} q_{e}^{2}}+\frac{\mathrm{t}}{q_{e}}
$$

Where $\mathrm{q}_{\mathrm{t}}(\mathrm{mg} / \mathrm{g})$ is the amount of adsorption at time $\mathrm{t}(\mathrm{min}), \mathrm{K}_{2}\left(\mathrm{~g} \mathrm{mg}^{-1} \mathrm{~min}^{-1}\right)$ is the rate constant of the pseudo-second order kinetic adsorption. The values of $\mathrm{K}_{2}$ and $\mathrm{q}_{\mathrm{e}}$ can be obtained from the intercept and slope of the plot of the experimental $t / q_{t}$ versus $t$. The experimental data which can be explained by the pseudo-second order kinetic model, with the correlation coefficient $\mathrm{R}^{2}$ being almost unity (0.99) for the lead ions. The experimental value of $\mathrm{K}_{2}$ was found to be $2.21 \times 10^{-2} \mathrm{~g} \mathrm{mg}^{-1} \mathrm{~min}^{-1}$, computing the intercept values from the plot that is based on kinetic model as shown in Figure 8.
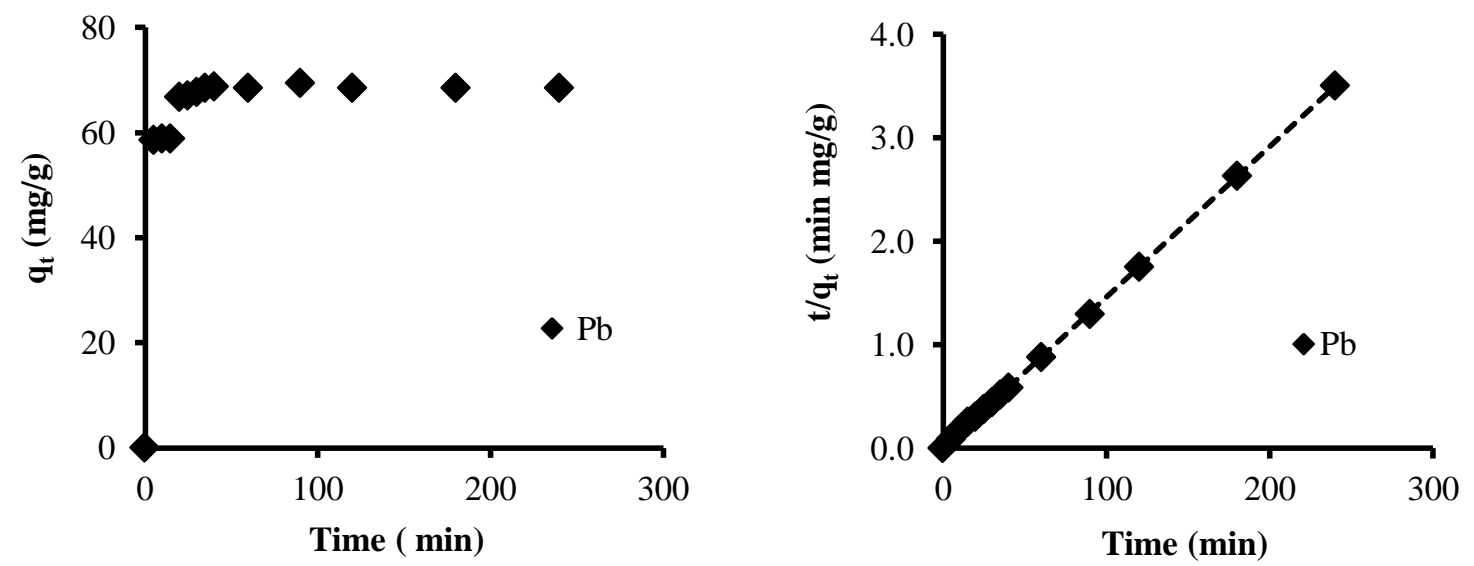

Figure 7 (left): Kinetic study for the adsorption of $\mathrm{Pb}^{2+}$ ion onto CASB Figure 8 (right): Pseudo-second order sorption kinetic for adsorption of $\mathrm{Pb}^{2+}$ ion onto $\mathrm{CASB}$

\section{Desorption Studies}

The regeneration of the sorbent may be crucially important for keeping the process costs down and to recover the pollutant extracted from the solution. In this studies, desorption was carried out by batch method for the evaluation of the adsorbed metals as well as the regeneration of the adsorbent. Pb (II) desorbed from CASB was found to be $96 \%$ using $0.1 \mathrm{M} \mathrm{HNO}_{3}$ as an eluting agent. After three cycles of operation the adsorption capacity decreased from $96 \%$ to $76 \%$. Regeneration of the CASB with $0.1 \mathrm{M}$ $\mathrm{CaCl}_{2}$ was efficient for further use. Here $76 \%$ desorption was achieved for $\mathrm{Pb}^{+2}$ with $0.1 \mathrm{M} \mathrm{HNO}_{3}$ solution. Thus the study reveals that the adsorbent can be reused which makes the process more economical and eco-friendly due to minimal solid waste generation. 
Table 3: Comparative adsorption capacity of $\mathrm{Pb}(\mathrm{II})$ onto different adsorbents at optimum $\mathrm{pH}$

\begin{tabular}{|l|c|c|c|}
\hline Adsorbent materials & $\begin{array}{l}\text { Adsorption } \\
\text { capacity }(\mathrm{mg} / \mathrm{g})\end{array}$ & $\mathrm{pH}$ & References \\
\hline $\begin{array}{l}\text { Modified Cassia grandish } \\
\text { (CG-g-PMMA) }\end{array}$ & 126 & 2 & 4 \\
\hline Saw dust carbon(SDC) & 199 & 5 & 2 \\
\hline Palm shell activated carbon & 95 & 3 & 19 \\
\hline Control Undaria pinnatifida & 302 & 4 & 20 \\
\hline $\begin{array}{l}\text { Charred xanthated sugarcane } \\
\text { bagasse(CXSB) }\end{array}$ & 327 & 4 & 5 \\
\hline CASB & 323 & 4 & This study \\
\hline
\end{tabular}

\section{Conclusions}

A novel charred aminated sugarcane bagasse (CASB) was prepared by two step reactions of CSB in which reduction with ammonia was followed by nitration. It was characterized and evaluated for its adsorption capacity of lead ion from its aqueous solution. The maximum adsorption capacity of $\mathrm{Pb}$ (II) onto the CASB was found to be higher than the reported value mentioned in the literature (Table 3 ). This indicates that the introduction of amine group onto charred sugarcane bagasse is of importance in enhancing the adsorption properties of raw sugarcane bagasse. Finally, it can be concluded that chemically modified aminated sugarcane bagasse might be low cost potential adsorbent in industrial wastewater as well as drinking water treatment.

\section{Acknowledgements}

The author would like to thank Prof. K. Inoue, Department of Applied Chemistry, Saga University, Japan for providing necessary laboratory facilities to perform this experimental work. The author is grateful to NAST, Nepal for providing partial financial assistant for this research work. Fruitful discussions with Associate Prof. Dr. K.N. Ghimire, CDC, Tribhuvan University is highly acknowledged.

\section{References}

1. R. Ayyappan, , A. Carmalin Sophia, K. Swaminathan, S. Sandhya, Process Biochem., 2005, 40, 1293.

2. A. Saeed, M. Iqbal, M.W. Aktar, Sep. Pure. Technol., 2005, 45, 25.

3. P. Pavasant, R. Apiratikul, V. Sungkhum, P. Suthiparinyanont, S. Wattanachira, T. Marhaba, Biores. Technol., 2007, 97, 2321.

4. V. Singh, S. Tiwari, A. K. Sharma, R. Sanghi, J. Colloid and Interface Sci., 2007, 316, 224.

5. P. L. Homagai, K. N. Ghimire, K. Inoue, Sep. Sc. Technol., 2011, 46, 330.

6. I. Gaballah, D. Goy, E. Allain, G. Kilbertus, J. Thauront, Met. Metall. Trans., 1997, 28, 13.

7. K. N. Ghimire, T. Miyajima, K. Yoshizuka, T. Shoji, Chitin and Chitosan Res., 2001, 7, 61.

8. C. Jeon, K. H. Park, Water Research, 2005, 39, 3938. 
9. L. Sene, A. Converti, M. G. A. Felipi, M. Zilli, Biores. Technol., 2002, 83, 153.

10. B. Xiao, X. F. Sun, R. Sun, Polymer Degradation and Stability, 2001, 71, 223.

11. R. R. Navarro, K. Sump, N. Fujii, M. Matsumura, Water Research, 1996, 30, 2488.

12. V. K. Gupta, I. Ali, J. Colloid Interface Sci., 2004, 271, 321

13. L.V. A. Gurgel, R.P. Freitas, L.F. Gil, Carbohydrate Polymers, 2008, 74, 922.

14. A. Atia, A. M. Donia, S. A. Abou-El-Enein, A. M. Yousif, Sep. Purif. Technol., 2003, 33, 295.

15. R. T. Morrison, R. N. Byod, Organic chemistry, $6^{\text {th }}$ ed, Printice - Hall of India Private Ltd. New Delhi. 1998, p.1176.

16. R. M. Silverstein, G. C. Bassler, T.C. Morril, Spectrometric Identification of Organic Compounds, John Wiley \& Sons., New York, 1981, p.95.

17. B. Volesky, S. Schiewer, Biosorption of metals in encyclopedia of bioprocess technology: fermentation, biocatalysis, and bioseparation", Wiley, New York, 1999, p.433.

18. Y. S. Ho, G. McKay, Process Biochem., 1999, 34, 451.

19. G. Issabayeva, M.K. Arooua, N. M. N. Sulaiman, Biores. Technol., 2006, 97, 2350.

20. Y. H. Kim, J. Y. Park, Y. J. Yoo, J. W. Kwak, Process Biochem., 1999, 34, 6. 